\title{
Partnership as a factor of companies' sustainable development in the Russian pipe industry
}

\author{
Natalya Izakova*, Ivan Vozmilov, and Tatiana Minina \\ Ural State University of Economics, 62, 8 Marta Street, 620144 Ekaterinburg, Russia
}

\begin{abstract}
Building partnerships with consumers in the industrial market, as well as responsible attitude to doing business contribute to companies' sustainable development, increasing satisfaction not only of consumers, but also of the society as a whole. The article analyzes various approaches to the problem of enterprises' sustainable development. A method is proposed for identifying criteria that affect the sustainability of industrial companies' development, including correlation analysis and the contingency table method. The characteristic of the Russian market of pipe products is presented. The hypothesis about the dependence of the industrial enterprises' sustainability development on the consumers' satisfaction in the industrial market with the experience of interacting with a supplier has been tested using the method of mathematical statistics. General principles of partnership were formulated based on the results of the study. The implementation of those principles is aimed at increasing company's stability in the pipe market.
\end{abstract}

\section{Introduction}

Building strong partnerships and collaborations between companies operating in the industrial market is a key aspect of sustainable economy. Partnership for sustainable development is directly linked to another goal - ensuring responsible consumption and manufacturing. Building partnerships between companies on common principles and values focused on meeting the interests of people and the planet allows organizing the technological process properly and achieving rational use of natural, human and material resources.

The pipe industry is the most important branch of the ferrous metallurgy. Its development largely determines the stability of the country's economy as a whole. The main consumers of tubular products are oil and gas industry, mechanical engineering, energy, housing and communal services and construction. The largest players in the Russian pipe market are the Pipe Metallurgical Company (TMK), the Chelyabinsk Pipe-Rolling Plant (ChTPZ), and the United Metallurgical Company (OMK). These enterprises are among the top ten leaders in the world steel pipe market. Russian steel pipe producers are mostly focused on the domestic market. The share of shipments to Russian consumers is growing every year. In 2015 this figure was $69 \%$, whereas in 2020 it reached the peak of $89 \%$. One of the main features of the

${ }^{*}$ Corresponding author: izakovan@gmail.com 
Russian market is that its capacity is determined primarily by the demand for large-diameter pipes associated with the construction of oil and gas pipelines. This segment has a significant impact on the environment. The construction of pipelines requires a particularly responsible attitude to the environment. It has now become a part of the portfolio of large companies that are looking for gaining access to perspective clients and contracts.

In 2020, the Russian pipe market was stagnating due to a slowdown in the growth of the Russian economy. In 2020, the demand for steel pipes was accounted for less than 9 million tons. This market capacity is a record low for the industry over the past 11 years. The total demand for pipe products decreased by 1,330 thousand tons and will amount in 2020 to $86.9 \%$ of previous year's indicator [1]. A further decline in demand for pipe products is going to be caused by the factors such as coronavirus pandemic, border closures, falling in oil prices, and a reduction in capex from the oil and gas sector [2].

Thus, the predicted unfavorable situation in the Russian pipe market confirms the unconditional need to maintain existing partnerships between companies, and create competitive advantages by ensuring responsible consumption and manufacturing.

The specifics of partners' interaction in the pipe market are dictated by environmental conditions, which have a significant impact on all market participants. The regulation of the Government of the Russian Federation as of September 19, 2018 on the control of the used pipes market has helped to ensure that market participants comply with the requirements of the legislation on waste management such as used pipes and re-sale restrictions. The driver of the industry growth is the trend towards regular modernization, improving pipe products with quality and safety being the key factors in the manufacturers' competitiveness that force partners to invest in improving manufacturability, durability and safety, as well as improving business processes of delivery, transaction support, and services.

Identifying and systematizing factors affecting the satisfaction of interaction between partners and the likelihood of repeat orders represent an urgent task for the participants in the pipe market. The relevance of the author's research is dictated by the need to systematize the factors that will make it possible to formulate the general principles of partnership, taking into account both values of companies participating in the pipe market, and the values and common goals focused on meeting the interests of humankind and the planet.

The purpose of this study is to highlight the criteria that have the major impact on the satisfaction with partner relations and the sustainability of the companies' development in the pipe industry under current conditions.

Most researchers identify economic, political, social and environmental factors that affect the sustainability of an enterprise $[3,4,5]$. The environmental aspect is currently coming to the fore, as it is key in developing state programs in order to ensure a decent way of life for present and future generations, It meets the needs of citizens and improves their quality of life, the process of stable growth of the main economic indicators of enterprises, regions and the country as a whole $[6,7,8 ; 9 ; 10]$. The problem of enterprises' sustainable development has been thoroughly researched by many scientists, but still remains insufficiently developed. The impact on the sustainability of enterprise development is considered either from the point of view of external environment or internal environment. The growth of economic potential and the financial stability of an enterprise are suggested as indicators of sustainable development [11]. The concept of enterprises' sustainable development is based on the ecological approach, which emphasizes the need to preserve the natural environment, as stated by I. S. Belik, L. V. Kamdina, N. V. Starodubets [12]. At the same time, most studies do not regard the role of partnerships with customers that directly affect the economic potential of an enterprise, its financial sustainability and environmental performance.

The authors of the current study believe that customer satisfaction with supplier relationships as well as the willingness to maintain and prolong those partnerships are the key aspects of enterprises' sustainable development. Maintaining partnerships with clients, 
having a portfolio of regular customers satisfied with an industrial company interaction increase the financial performance and growth of the economic potential of the enterprise and allow to better "fit" into market interactions and more flexibly respond to changes in market conditions [13]. In this sense, it becomes necessary to identify and systematize criteria that have a significant impact on satisfaction with partnerships and the sustainability of industrial companies.

\section{Materials and Methods}

The industrial enterprise sustainability development $(\mathrm{Y})$ is proposed to be considered as a function of dependence between customer satisfaction in the industrial market and the experience of interaction with a supplier $(\mathrm{X})$ :

$$
Y=F(X)
$$

There is a correlation: the higher the level of customer satisfaction in the industrial market, the greater the likelihood of repeat orders, which increases the level of financial stability and economic efficiency of the industrial enterprise. Satisfaction, in turn, depends on the criteria that characterize the experience of interaction with the supplier.

In order to identify and systematize the criteria that have a significant impact on satisfaction with partnerships and sustainability of industrial companies, the authors propose to use a comprehensive methodology based on testing hypotheses regarding the relationship between the criteria that characterize the experience of interaction with a supplier and the level of customer satisfaction, as well as the likelihood of further interaction and repeat orders (figure $1)$.

\begin{tabular}{|c|c|c|}
$\begin{array}{c}\text { Input } \\
\text { Criteria of experience } \\
\text { in interacting with } \\
\text { suppliers }\end{array}$ & $\begin{array}{c}\text { Methods } \\
\text { Correlation analysis } \\
\text { The contingency table } \\
\text { method }\end{array}$ \\
$\begin{array}{c}\text { Output } \\
\text { The likelihood of } \\
\text { further interaction }\end{array}$
\end{tabular}

Fig. 1. Methodology for identifying criteria affecting the sustainability of industrial companies' development

The following criteria characterizing the experience of interaction with the supplier were selected by the authors: width and variety of the product range, product quality, product compliance with environmental safety standards, price, shipment and delivery process, aftersales service, product use experience, solving problems and controversial issues, professionalism of managers, the speed of response to requests. In order to assess the criteria suggested, it was proposed to conduct a survey of industrial enterprise partners, as a result of which company representatives would give a score (from 1 to 7 ) of the importance of each criterion for deciding on further interaction and repeated orders of products. The probability of making repeat orders is proposed to be estimated from 0 to $100 \%$, with the general level of interactions satisfaction varying between 1 to 10 , where 1 is 'absolutely not satisfied' and 10 accounts for 'absolutely satisfied'.

For evaluating those criteria, the methods of correlation analysis and contingency tables were selected. Since all the considered criteria and indicators are quantitative variables, these methods will provide an accurate assessment of the presence or absence of a relationship between them.

Research hypothesis. 
The level of satisfaction and the likelihood of repeat orders by consumers of different industries are influenced with different strengths by the criteria that characterize the experience of interacting with the company.

Based on the results of the analysis, it is possible to identify the influence of environmental factors on consumer satisfaction in the industrial market.

\section{Results and Discussion}

The methodology put forward by the authors was tested on the example of the JSC Trading House 'Uraltrubostal', which represents a part of the pipe division of the 'Chelyabinsk Tube Rolling Plant' (hereinafter the ChTZ Group) industrial group, one of the largest Russian pipe manufacturers. JSC TH 'Uraltrubostal' has been selling pipe products of the ChTZ Group in the market. The authors conducted a consumer survey. The sample included 52 companies from various industries: metal structure manufacturers $-5 \%$, petrochemical industry $-7 \%$, industrial heat exchange equipment manufacturers - $12 \%$, machinery, equipment and vehicles $-24 \%$, metal machining and metal traders $-27 \%$ each. The study period spans from November 01, 2020 to March 30, 2021. In order to identify the influence of the criteria characterizing the experience of interaction with the company on the level of satisfaction and the likelihood of repeated orders, the authors conducted a pair correlation analysis performed with the usage of the Statistical Package for the Social Science software package (Table 1).

Table 1. Pairwise correlations of the satisfaction level, the likelihood of reordering and the experience of interaction with JSC TH 'Uraltrubostal'

\begin{tabular}{|c|c|c|c|c|}
\hline \multirow{2}{*}{ Interaction experience criteria } & \multicolumn{2}{|c|}{ Satisfaction level } & \multicolumn{2}{c|}{$\begin{array}{c}\text { Probability of } \\
\text { reordering }\end{array}$} \\
\cline { 2 - 5 } & R-Pearson & Signif. & R-Pearson & Signif. \\
\hline Width and variety of the product range & 0.682 & 0.000 & 0.565 & 0.000 \\
\hline Product quality & 0.087 & 0,587 & 0.042 & 0.793 \\
\hline $\begin{array}{c}\text { Product compliance with environmental safety } \\
\text { standards }\end{array}$ & 0.679 & 0.005 & 0.605 & 0.007 \\
\hline Price & 0.622 & 0.000 & 0.536 & 0.004 \\
\hline Shipment and delivery process & 0.582 & 0.000 & 0.513 & 0.001 \\
\hline After-sales service & 0.212 & 0.183 & 0.069 & 0.668 \\
\hline Product use experience & 0.010 & 0.952 & -0.144 & 0.368 \\
\hline Solving problems and controversial issues & 0.601 & 0.000 & 0.241 & 0.129 \\
\hline Professionalism of managers & 0.289 & 0.067 & 0.275 & 0.081 \\
\hline Speed of response to requests & 0.432 & 0.005 & 0.200 & 0.210 \\
\hline
\end{tabular}

The analysis resulted in obtaining correlations, leading to the following conclusions:

1. The level of customer satisfaction with the interaction with JSC TH 'Uraltrubostal' is influenced by the following criteria of interaction experience with the company: width and variety of the product range $(\mathrm{R}-\mathrm{Pearson}=0.682)$, product compliance with environmental safety standards $(\mathrm{R}-\mathrm{Pearson}=0.679)$, price $(\mathrm{R}-\mathrm{Pearson}=0.622)$, shipment and delivery process $(\mathrm{R}-\mathrm{Pearson}=0.582)$, solving problems and controversial issues $(\mathrm{R}-\mathrm{Pearson}=0.582)$. This conclusion confirms the corresponding level of reliability of the results obtained, since the value of the 'Significance' indicator for all of the listed criteria is less than 0.05 .

2. The likelihood of repeat orders and prolonging the interaction of a company with JSC $\mathrm{TH}$ 'Uraltrubostal' is more influenced by such criteria as the width and variety of the product range $(\mathrm{R}-\mathrm{Pearson}=0.565)$, product compliance with environmental safety standards $(\mathrm{R}$ Pearson $=0.605)$, price $(\mathrm{R}$-Pearson $=0.536)$, shipping and delivery process $(\mathrm{R}-$ Pearson $=$ $0.513)$. Confidence scores are also significantly high.

3. It is worth paying attention to the fact that the criterion 'product compliance with environmental safety standards' has a high impact on both the level of satisfaction and the likelihood of repeat purchases. It can be assumed that this fact is due to the legal requirements 
for the technical characteristics of pipe products, which should ensure the environmental safety of their further operation.

4. As a result of the analysis using the contingency tables method, it was possible to reveal that the criterion 'product compliance with environmental safety standards' is the most important for companies in the petrochemical industry (average score 6.7), as well as for manufacturers of machinery, equipment and vehicles (average score 6.2). Manufacturers of steel structures and industrial heat exchange equipment chose 'price' (average score 6.8) and "shipping and delivery process" (average score 6.1) as the most important criteria. For metal traders, the most important criteria are 'price' and 'width and variety of the product range' which might be explained with the fact that these companies have been engaged in the resale of pipes.

5. Correlation analysis confirmed the dependence of the likelihood of tubular products reordering on the level of customer satisfaction (R-Pearson $=0.626$; Significance $=0.000$ ).

On the basis of the selected criteria characterizing the experience of interaction between companies in the pipe market, the authors formulated the general principles of partnership, the implementation of which is aimed at increasing the stability of the company in the pipe market:

- releasing products that comply with environmental safety standards, compliance with the requirements of legislation on waste management (used pipes), exclusion of used pipes from re-sale;

- production of a unique product range and execution of technically complex orders, regular modernization, improvement, inclusion of new types of products in the assortment;

- competent pricing policy focused on competitors' prices;

- expanding the regions of presence, creating new warehouse sites, which will optimize the shipment process and increase the speed of delivery of pipe products to the consumer;

- organization of prompt feedback with partners to quickly resolve problems and controversial issues.

\section{Conclusion}

The purpose of developing a methodology for identifying and systematizing criteria affecting the sustainability of industrial companies is to formulate the principles of partnership, taking into account both the values of the companies participating in the pipe market and the values and common goals aimed at meeting the interests of people and the planet. The implementation of these principles in accordance with the interaction between partners in the pipe market increases the sustainability of the pipe industry companies in present-day conditions.

The Joint Stock Company Trading House 'Uraltrubostal' was chosen as the object of this research. This company represents a part of the pipe division of the 'Chelyabinsk Pipe Rolling Plant' industrial group. With the help of pair correlation analysis and the contingency table method, the criteria influencing the sustainability of the development of industrial companies in the Russian pipe market are identified. With the help of pair correlation analysis and the contingency table method, the criteria influencing the industrial companies' sustainability development in the Russian pipe market were identified. Information analysis was carried out by the authors in 2021 . The methodology suggested by the authors allows conducting a regular analysis of the criteria that affect the likelihood of repeat orders, in order to adjust and implement the principles that allow maintaining interaction with priority partners and increasing the stability of the company.

The results of the study for industrial companies in the pipe market showed the particular importance of compliance with environmental safety standards for making a decision to 
continue interaction with pipe manufacturers for companies in the petrochemical industry and manufacturers of machinery, equipment and vehicles.

In order to obtain more complete and relevant information, it is planned to continue the research and study the influence of the criteria characterizing the experience of interaction with the company on the financial performance of industrial enterprises operating in the pipe market.

\section{References}

1. The Russian pipe market demonstrates stability (Oilcapital, 2019)

2. The pipe market is discussing consolidation scenarios amid weak demand (Interfax, 2020)

3. S. V. Orekhova, J Adv. Res. L. Econ., 7(7), 1798 (2016)

4. E. Seyedsayamdost, Ess. Conc. Glob. Env. Gov., 332 (2020)

5. E. Yu Kuznetsova., O. O. Podolyak, S. V. Kuznetsov, J New Econ., 21(4), 131 (2020)

6. J. T.Scott, The Sustainable business a practitioner's guide to achieving long-term profitability and competitiveness, 236 (2013)

7. N. C. Onat, M. Kucukvar, A. Halog, S. Cloutier, Sustainability, 9(5), 706 (2017)

8. N. J. Bennett, A. M. Cisneros-Montemayor, J. Blythe, J. J. Silver, G. Singh, N. Andrews, U. R. Sumaila, Nat. Sust., 2, 991 (2019)

9. D. Messner, S. Schlacke, M. Fromhold-Eisebith, U. Grote, E. Matthies, K. Pittel, N. Wegener, Digital momentum for the UN Sustainability Agenda in the 21st century, 28 (2019)

10. S. Fukuda-Parr, B. Muchhala, W Devel., 126 (2019)

11. A. Domnikov, G. Chebotareva, M. Khodorovsky, Int. J Sust. Devel. Plan., 13(2), 349 (2018)

12. I. S. Belik, L. V. Kamdina, N. V. Starodubets, Ec. Reg. 4 (15), 1156 (2019)

13. N.B. Izakova, L.M. Kapustina, Upr. - Th Man. 9(5), 74 (2018) 